Original Research Article

\title{
Drug utilization pattern in orthopaedic outpatient department of a tertiary care hospital in Kerala: a geriatric perspective
}

\author{
Sini K., N. K. Mohammed Basheer, Shaikh Ubedulla Shaikh Iqbal Daud*, Divya G. Krishnan
}

Department of Pharmacology, KMCT Medical College, Kozhikode, Kerala, India

Received: 18 April 2018

Accepted: 22 May 2018

*Correspondence to:

Dr. Shaikh Ubedulla Shaikh

Iqbal Daud,

Email: drubaidulla@gmail.com

Copyright: (C) the author(s), publisher and licensee Medip Academy. This is an openaccess article distributed under the terms of the Creative Commons Attribution NonCommercial License, which permits unrestricted noncommercial use, distribution, and reproduction in any medium, provided the original work is properly cited.

\begin{abstract}
Background: Geriatric population due to the age related changes in pharmacokinetics and pharmacodynamics and the presence of comorbidities is vulnerable to drug interactions, adverse effects and high cost of therapy. This necessitates a periodic review of DU pattern in the geriatric population to ensure safe and effective treatment for them. The present study was undertaken to evaluate the DU pattern for medical conditions among the geriatric population in the Orthopaedic outpatient department (OPD) of a tertiary care hospital in Kerala. Methods: In this cross sectional observational study conducted in the Orthopaedics OPD of a tertiary care hospital, prescriptions were collected from patients attending the Orthopaedics OPD randomly over a period of 6 months. Out of these, prescriptions of male and female patients of age more than 60 years were sorted and analysed using World Health Organization drug prescribing indicators as well as additional parameters and the data was presented in the form of frequency and percentages using tables and charts.

Results: A total of 800 prescriptions were collected and studied of which 76 $(9.5 \%)$ belonged to patients from the geriatric population. Majority of the patients were in the age group of 61-70years $(52.63 \%)$. Spondylosis $(42.10 \%)$ was the most common indication for patients attending Orthopaedics OPD. Average number of drugs per prescription was 3.05 with a range between 1 and 5. Only $5.17 \%$ drugs were prescribed using generic name. Utilization from the essential drug list was $39.65 \%$. The percentage of encounters in which an antibiotic and injection prescribed was $0 \%$ and $10.34 \%$ respectively. Of the total drugs prescribed $35 \%$ were FDCs. The most routinely prescribed drugs among the various classes were NSAIDs $34 \%$ followed by gastroprotectives $(25 \%)$. The assessment of prescriptions with regard to completion and legibility was satisfactory.

Conclusions: Current study pointed out deficiencies like polypharmacy, low prescribing of drugs by generic names, low prescribing of drugs from the essential drug list and higher use of FDCs. Use of antibiotics and injections was satisfactory and acceptable. Legibility and completion of prescription format was largely satisfactory. Proper strategies to rectify these deficiencies can ensure safe and effective treatment for geriatric patients.
\end{abstract}

Keywords: Drug utilization, Essential drug list, Geriatric, Generic name

\section{INTRODUCTION}

Drug utilization (DU) has been defined as 'the marketing, distribution, prescription and use of drugs in a society, with special emphasis on the resulting medical, social and economic consequences (WHO Expert Committee, 1977). ${ }^{1}$ The assessment of DU is important for clinical, educational and pharmaco-economic purposes. $^{2}$ The ultimate purposes of DU studies are to contribute to the 
optimal quality of drug therapy by identifying, documenting and analysing problems in the use of drugs.

Geriatrics is a branch of medicine concerned with the clinical, preventable, remedial and social aspects of illness in elderly. ${ }^{3}$ The geriatric population is a group that is vulnerable to many diseases and drug related problems. Pharmacokinetic profiles of drugs change considerably in the elderly because of reduced body water, renal and hepatic function and increased body fat. Multiple drug use and polypharmacy is extremely common in elderly divulging them to drug interactions, adverse effects and increased cost of therapy. Inter individual differences in age related pharmacokinetic and pharmacodynamic changes as well as co-morbid conditions should reflect while prescribing medicines in elderly population. ${ }^{4}$

This necessitates a periodic review of DU pattern in the geriatric population to ensure safe and effective treatment for them. In this background, the aim of the present study was to evaluate the DU pattern for medical conditions among the geriatric population in the Orthopaedic outpatient department (OPD) of a tertiary care hospital in Kerala. The objectives of the study were to study the demographic pattern and the distribution of different orthopaedic conditions encountered among the elderly in the orthopaedic OPD, to analyse the prescriptions using the WHO prescribing indicators and to analyse the usage pattern of different drug classes as well as percentage of FDC usage in the prescriptions.

\section{METHODS}

A cross sectional prospective study was conducted in the Orthopaedics OPD of our centre at Kerala after obtaining ethical clearance from the Institutional Ethics Committee. We collected eight hundred (800) prescriptions of pattern with non- surgical/non traumatic orthopaedic conditions randomly over a period of 6 months. Out of these, prescriptions of male and female patients of age more than 60 years were sorted and analysed separately for the parameters:

\section{- Demography}

- Distribution of different orthopaedic conditions

- WHO Prescribing Indicators: Average number of drugs per encounter, percentage of drugs prescribed by generic name, percentage of encounters with an antibiotic, percentage of encounters with an injection and percentage of drugs prescribed from essential drugs list.

- Usage pattern of different drug classes

- $\quad$ Percentage of Fixed dose combinations (FDC) usage in the prescriptions.

- Completion of prescriptions (percentage of prescriptions with correctly written diagnosis, dose, dosage form, frequency and duration of drug administration). Also, the percentage of prescriptions which were legible was calculated.
Data were entered and analysed using Microsoft Excel 2007. Data was presented in the form of frequency and percentages using tables and charts.

\section{RESULTS}

Out of the 800 prescriptions, $76(9.5 \%)$ prescriptions were of geriatric population. The total number of drugs prescribed in geriatric group was 232 .

The demographic data (Table 1) shows that majority of the patients were in the age group of $61-70$ years $(52.63 \%)$ followed by age group of 71-80 years $(42.13 \%)$; the lowest number of patients $(5.2 \%)$ were in the age group of $81-90$ years. Out of the total patients, $36.84 \%$ were males and $63.16 \%$ were females.

Table 1: Demographic data of patients.

\begin{tabular}{|llll|}
\hline Parameters & Groups & $\begin{array}{l}\text { Number of } \\
\text { patients }\end{array}$ & $\begin{array}{l}\text { Percentage } \\
\text { of patients }\end{array}$ \\
\hline \multirow{2}{*}{$\begin{array}{l}\text { Age (in } \\
\text { years) }\end{array}$} & $61-70$ & 40 & 52.63 \\
\cline { 2 - 4 } & $71-80$ & 32 & 42.11 \\
\hline \multirow{2}{*}{ Gender } & $81-90$ & 4 & 5.26 \\
\cline { 2 - 4 } & Males & 28 & 36.84 \\
\hline
\end{tabular}

Study of the distribution of different orthopaedic conditions among geriatric patients (Table 2) showed that the orthopaedic condition which was the most common cause for attending OPD was spondylosis (41\%) followed by arthritis (16\%) and neuralgic pain (16\%). Multiple disc generations $(11 \%)$ and low back ache $(10 \%)$ were the other orthopaedic conditions seen in geriatric patients attending the OPD. Plantar fasciitis was seen in 5\% of patients.

\section{Table 2: Distribution of different orthopaedic conditions among geriatric patients.}

\begin{tabular}{|lll|}
\hline Orthopaedic condition & $\begin{array}{l}\text { Number } \\
\text { of patients }\end{array}$ & Percentage \\
\hline Spondylosis & 31 & $42 \%$ \\
\hline Arthritis & 12 & $16 \%$ \\
\hline Neuralgic pain & 12 & $16 \%$ \\
\hline Low back ache (LBA) & 09 & $11 \%$ \\
\hline $\begin{array}{l}\text { Multiple disc } \\
\text { degeneration }\end{array}$ & 08 & $10 \%$ \\
\hline Plantar fascitis & 04 & $05 \%$ \\
\hline
\end{tabular}

Table 3 shows WHO prescribing indicators. Average number of drugs per prescription was 3.05 ranging from 1 to 5 . Percentage of drugs prescribed by generic name was $5.17 \%$. Percentage of drugs prescribed from essential drug list was $39.65 \%$. Antibiotics were not prescribed in any of the prescriptions. Percentage of encounters in which injection prescribed was $10.34 \%$.

Most commonly prescribed drugs were NSAIDs (34\%) followed by gastroprotective agents (25\%), 
methylcobalamine with gabapentine $(17 \%)$, calcium with vitamin D (12\%), enzymes (5\%), others (7\%) (Table 4).

Table 3: Assessment of WHO prescribing indicators.

\begin{tabular}{|ll|}
\hline $\begin{array}{l}\text { WHO Prescribing indicators } \\
\text { assessed }\end{array}$ & Result \\
\hline $\begin{array}{l}\text { Average number of drugs per } \\
\text { prescription }\end{array}$ & 3.05 \\
\hline $\begin{array}{l}\text { Percentage of drugs prescribed } \\
\text { from essential drug list }\end{array}$ & $\begin{array}{l}39.65 \% \\
(92 \mathrm{drugs})\end{array}$ \\
\hline $\begin{array}{l}\text { Percentage of drugs prescribed by } \\
\text { generic name }\end{array}$ & $\begin{array}{l}5.17 \% \\
(12 \mathrm{drugs})\end{array}$ \\
\hline $\begin{array}{l}\text { Percentage of encounters in which } \\
\text { antibiotic prescribed }\end{array}$ & $0 \%$ \\
\hline $\begin{array}{l}\text { Percentage of encounters in which } \\
\text { injection prescribed }\end{array}$ & $10.34 \%$ \\
\end{tabular}

Table 4: Commonly prescribed drugs among geriatric patients attending orthopaedic OPD.

\begin{tabular}{|lll|}
\hline Drug & Number & $\begin{array}{l}\text { Percentage of total } \\
\text { drugs prescribed }\end{array}$ \\
\hline NSAIDs & 79 & $34 \%$ \\
\hline Gastroprotectives & 58 & $25 \%$ \\
\hline Methylcobalamin & 39 & $17 \%$ \\
\hline $\begin{array}{l}\text { Calcium with } \\
\text { Vitamin D }\end{array}$ & 28 & $12 \%$ \\
\hline Enzymes & 12 & $05 \%$ \\
\hline Others & 16 & $07 \%$ \\
\hline
\end{tabular}

Out of the total drugs prescribed, $35 \%$ were fixed dose combinations. The FDCs encountered mostly in this study were combinations of either vitamins or analgesics (Figure $1)$.

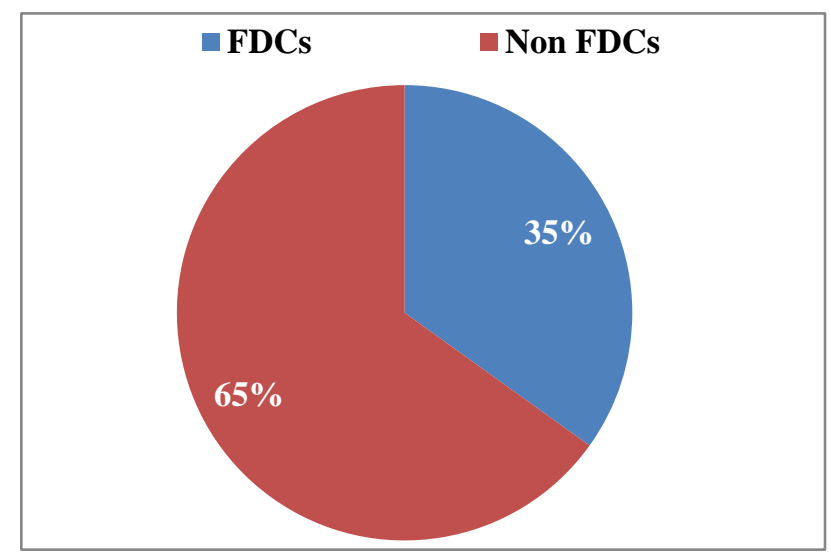

Figure 1: Distribution of FDCs and non FDCs in the prescriptions of geriatric patients.

While dosage form, dose, frequency of the drug administration was written in all the prescriptions, dosage form and duration of treatment was mentioned in $94.7 \%$ of the prescriptions. $89.4 \%$ of the prescriptions were legible. (Table 5).
Table 5: Other observations.

\begin{tabular}{|ll|}
\hline Observation & Comment \\
\hline Diagnosis & $\begin{array}{l}\text { Written in 18 (94.7\%) of } \\
\text { prescriptions }\end{array}$ \\
\hline Dose of drug & Written in all prescriptions \\
\hline $\begin{array}{l}\text { Frequency of drug } \\
\text { administration }\end{array}$ & Written in all prescriptions \\
\hline Duration of treatment & $\begin{array}{l}\text { Written in 18 (94.7\%) of } \\
\text { prescriptions }\end{array}$ \\
\hline Dosage form & Written in all prescriptions \\
\hline $\begin{array}{l}\text { Legibility of } \\
\text { prescriptions }\end{array}$ & $\begin{array}{l}17(89.4 \%) \text { of prescriptions } \\
\text { were legible }\end{array}$ \\
\hline
\end{tabular}

\section{DISCUSSION}

In this study, out of 800 prescriptions, 76 (9.5\%) prescriptions belonged to the geriatric age group. Majority of the patients $(52.63 \%)$ were in the age group of 61-70 years. This is comparable to the study done by Febin et al. ${ }^{5}$ In this study $36.8 \%$ of patients were males and $63.1 \%$ were females. This is in contrast to the study done by Shah et al where there was a male preponderance over female. ${ }^{6}$ Majority of the patients came with the indication of spondylosis (42.10\%) followed by arthritis (15.7\%) and neuralgic pain $(15.7 \%)$.

The average number of drugs per prescription is an important prescribing indicator as per WHO in the analysis of any prescription. ${ }^{7}$ It is preferable to keep the number of drugs per prescription as low as possible since polypharmacy leads to increased risk of drug interaction, increased hospital cost, errors of prescribing, adverse effects and increased cost to the patient. ${ }^{8}$ In this study, the average number of drugs per prescription was 3.05 ranging from 1 to 5 drugs per prescription as shown in Table 2 . This finding is not acceptable when compared with the standard (i.e. 1.6-1.8 drugs per prescription) recommended by the WHO. ${ }^{9}$ However, it is lower than the average number of drugs per prescription in studies by Taskeen et al, where it was 6.07 and Kumar et al where it was 6.33..$^{10,11}$

Percentage of drugs prescribed from essential drug list is another WHO prescribing indicator that was analysed. Essential drug list is intended to have a positive impact on the availability and rational use of medicines. This study shows that the percentage of drugs that were prescribed from essential drug list was $39.65 \%$ as shown in Table 2. Febin et al, in their study showed that the percentage of drugs prescribed from essential drug list was $65.15 \%$. Similar study done by Jhaveri et al, and Thiruthopu et al, showed the percentage of drugs prescribed from essential drug list to be $50 \%$ and $49.78 \%$ respectively. ${ }^{12,13}$ Compared to all the reference studies, the percentage of drugs prescribed from essential drug list was lower in the present study. The finding in the study concludes the need for increasing access to essential medicines in the department of Orthopaedics for the rational use of 
medicines, to improve health status and for development gains.

In current study, the percentage of drugs prescribed using generic name was just $5.17 \%$ as shown in Table 3 . This is lower than the WHO standard value of $100 \% .{ }^{14}$ The percentage of drugs prescribed by generic drugs has been shown to be low in studies by Febin et al, and Taskeen et al, where it was $12.60 \%$ and $10.08 \%$ respectively. All these studies including present study indicate that brand names are more frequently used than generic names and are more popular among practitioners and their prescribing behaviour may be due to the direct influence by various drug company representatives. ${ }^{15}$

In this study the percentage of encounters in which an antibiotic was prescribed was $0 \%$ as shown in Table 3, which is acceptable and less than the WHO standard value (20.0\%-26.8\%). This could be attributed to the fact that the use of antibiotics in Orthopaedics is more prevalent in the IPD than OPD. This fact explains the lower percentage of antibiotic use in the present study wherein only OPD prescriptions were included. Moreover, the disease distribution in this study points to chronic orthopaedic conditions without any infectious etiology which routinely does not require an antibiotic.

Minimum use of injections is preferred, and this reduces the risk of infection through parenteral route and cost incurred in therapy. The percentage of encounters in which an injection was prescribed in this study was $6 \%$ as shown in Table 2, which is acceptable and less than the WHO standard value $(13.4 \%-24.1 \%)$ derived to serve as ideal. The percentage of injection use in this study was much lower than the study by Febin et al, in which it was $95.12 \%$. The higher percentage of injections in this reference study is possibly explained by the inclusion of IPD prescriptions also along with OPD prescriptions.

The most commonly used drug class was NSAIDs (34\%). In this study, anti-ulcer drugs $(25 \%)$ prescribed was much less than the NSAIDs. This indicates that anti-ulcer drugs were not routinely prescribed along with the NSAIDs at our center. The routine use of FDCs is irrational. Inappropriate use of unwanted drugs in the combination may lead to adverse effect or drug interactions. Use of FDCs should be avoided unless necessary. Out of the total drugs prescribed, $34.48 \%$ were fixed dose combinations. This was higher than in other similar studies done by Veena et al and Jhaveri et al, wherein it was $14.87 \%$ and $17.87 \%$ respectively.

With respect to completion of prescriptions and legibility, the prescriptions analysed in the present study appeared to be satisfactory.

\section{CONCLUSION}

This study recognized both salient features as well as deficiencies in the prescribing pattern among geriatric patients in the Orthopaedics OPD. While the deficiencies pointed out in this study are polypharmacy, low prescribing of drugs by generic names, low prescribing of drugs from the essential drug list and higher use of FDCs, the salient features include a fair use of antibiotics and injections. Also, the prescriptions were satisfactory and complacent with rational prescribing with regards to completion and legibility of prescriptions. Hence the present study shows that there is considerable scope of improvement in the prescribing practices. Proper strategies taken to overcome the inadequacies pointed out by this study can ensure the rational use of medicines in the geriatric population.

\section{ACKNOWLEDGEMENTS}

Authors would like to thank all the participants for sparing their valuable time for betterment of science.

Funding: No funding sources

Conflict of interest: None declared

Ethical approval: The study was approved by the Institutional Ethics Committee

\section{REFERENCES}

1. Laporte JR, Porta M, Capella D. Drug utilization studies: a tool for determining the effectiveness of drug use. Br J Clin Pharmac. 1983;16:301-4.

2. Mhetre. study of pattern of drug usage in an urban area. IJP. 2003;35:316-7.

3. Gopinath S, Rajalingam B, Sriram S, Vijayakumar S. Amn individual based study of geriatric population: a polypharmacy. Int J Pharm Sci. 2011;3(4):63-6.

4. Veena DR, Padma L, Patil S. Drug prescribing pattern in elderly patients in a teaching hospital. J Dental Med Sci. 2012;1:39-42.

5. Abraham F, Varughese G, Mathew JC, John PM, Sam GK. Drug utilization pattern among geriatric patients in a tertiary care teaching hospital. Asian J Pharm Clin Res. 2015;8(6):1991-4.

6. Shah V, Mehta DS. Drug utilization pattern at medicine OPD at tertiary care hospital at Surendranagar. Int J Biomed Adv Res. 2014;5(2):802.

7. GAMA, Helena. Drug Utilization Studies. Arq Med. [online]. 2008;22(2-3):69-74.

8. Pradhan SC, Shewade DG, Tekur U, Zutshi S, Pachiappan D, Dey AK, et al. Changing pattern of antimicrobial utilization in an Indian teaching hospital. Int J Clin Pharmacol Ther Toxicol. 1990;28(8):33943.

9. Assefa A. Assessment of drug use pattern using WHO prescribing indicators at Hawassa University teaching and referral hospital, south Ethiopia: across-sectional study. BMC Health Services Research. 2013;13:170.

10. Taskeen M, Anitha N, Ali RS, Bharath R, Khan BA. A study on rational drug prescribing pattern in Hyderabad. J of Dru Deliv and Thera. 2012;2(5):10913,109 . 
11. Kumar RT, Shahina S, Shobha JC, Naidu MU, Rani UP, Vijay T. Drug utilization in geriatric population in a Tertiary Care Centre. Jammu and Kashmir Sci. 1999;1(3):118-20.

12. Jhaveri BN, Patel TK, Barvaliya MJ, Tripathi CB. Drug utilization pattern and pharmacoeconomic analysis in geriatric medical in-patients of a tertiary care hospital of India. $\mathbf{J}$ of Pharma and Pharmacothe. 2014;5(1):15-20.

13. Thiruthopu SN, Mateti VU, Bairi R, Sivva D, Martha S. Drug utilization pattern in South Indian pediatric population: A prospective study. Perspect Clin Res. 2014;5(4):178-83.
14. Mahalli A. WHO/INRUD drug prescribing indicators at primary health care centres in Eastern province, Saudi Arabia. East Mediterr Health J. 2012;18(11).

15. Joshi MP, Sugimoto T, Santoso B. Pharmacoepidemiology and drug safety. 1997;6:41721.

Cite this article as: Sini K, Basheer NKM, Daud SUSI, Krishnan DG. Drug utilization pattern in orthopaedic outpatient department of a tertiary care hospital in Kerala: a geriatric perspective. Int J Basic Clin Pharmacol 2018;7:1314-8. 